\title{
The Improvement of Surface Quality of Continuous Rheocast Bars of Steel and High Melting Point Alloys
}

\author{
Kenneth E. BLAZEK and James E. KELLY \\ Inland Steel Research and Development Laboratory, 3001 E. Columbus Dr., E. Chicago, IN 46307, USA.
}

(Received on August 28, 1996; accepted in final form on November 12, 1996)

\begin{abstract}
A new continuous rheocasting process for steels and high temperature alloys has been developed by Inland Steel incorporating a dual chamber casting machine utilizing separate electromagnetic stirrers around each chamber. Initial casts on the rheocaster were plagued by breakouts and very rough as-cast surface morphology. The mechanism for solidification and formation of cast surface morphologies on as-rheocast bars has been determined and verified by comparing predicted surface morphologies to actual surface morphologies. The mechanism was then used to develop new withdrawal patterns to eliminate sticker breakouts and obtain good surface quality.
\end{abstract}

KEY WORDS: continuous casting; rheocasting; steel; high temperature alloys; surface quality; solidification structure.

\section{Introduction}

Inland Steel successfully developed a continuous rheocaster for steels and other high temperature alloys. ${ }^{1)}$ Due to the high stirring intensity and shear force provided to the solidifying metal, the dendrites which form as the metal is cooled through the liquid-solid region are rounded. This round dendrite shape is now commonly referred to as degenerate dendrites. As solidification occurs, the degenerate dendrites are surrounded by liquid and the viscosity of the semi-solid responds in a rheological manner to the application of shear force. Because of the rounded nature of the degenerate dendrites, this semi-solid slurry could be deformed with very low forming pressures at semi-solid temperatures into very intricate shapes without hot tearing. The semi-solid slurry could also be rapidly solidified from the semi-solid region into a cast section. These cast sections could then be cut into smaller sections if necessary, reheated back into the semi-solid temperature range, handled as a solid, and formed into intricate shapes as done directly with the semi-solid slurry. Successful structure modification to provide a fine degenerate dendrite size, small peripheral dendritic zone, and minimum percent dendricity via this casting process has been attained for all grades attempted which have included carbon steels from 0.05 to 1.0 mass $\%$ carbon, ferritic stainless steel ( 1 mass $\%$ C, 0.2 mass $\% \quad \mathrm{Mn}$, 0.5 mass $\%$ Si, 0.1 mass $\%$ Ni, 16 mass $\% \mathrm{Cr}, 0.5$ mass $\%$ Mo), austenitic stainless steel (0.05-0.15 mass \% C, 1.5 mass $\%$ Mn, 0.6 mass $\%$ Si, 9-1 1 mass $\% \mathrm{Ni}, 19$ mass $\%$ $\mathrm{Cr}, 0.4-2.2$ mass $\% \mathrm{Mo}$ ), alloy steels, tool steels (1 mass $\%$ C, 0.4 mass $\%$ Mn, 0.5 mass $\% \mathrm{Si}, 0.2$ mass $\% \quad \mathrm{Ni}, 4.1$ mass $\% \mathrm{Cr}, 8.8$ mass $\% \mathrm{Mo}, 0.1$ mass $\% \mathrm{Al}, 2.1$ mass $\% \mathrm{~V}$,
1.8 mass $\% \mathrm{~W}, 0.5$ mass $\% \mathrm{Co}$ ), and even a Hastelloy $\mathrm{X}$ (0.1 mass $\%$ C, 0.25 mass $\% \mathrm{Mn}, 0.5$ mass $\% \mathrm{Si}, 0.7 \mathrm{mass} \%$ $\mathrm{W}, 22 \mathrm{mass} \% \mathrm{Cr}, 0.6$ mass $\%$ Co, 10 mass $\%$ Mo, 54 mass $\% \mathrm{Ni}$, and balance $\mathrm{Fe}$ ).

\section{Defects and Operational Problems after Initial De- velopment}

Two problems which appeared at the completion of the initial development of the continuous rheocaster were sticker breakouts and variable surface quality. The sticker breakout problem has been solved by changing the withdrawal cycle from $3 \mathrm{~Hz}$ push-pull cycle to a cycle consisting of constant speed withdrawal for a time duration of 3 to $10 \mathrm{sec}$, a push back of a couple of millimeters and a hold period of 3 to $10 \mathrm{sec}$. This technique was developed as a result of experimental work done on the pilot caster. ${ }^{1)}$ This work indicated that the time necessary for healing the hot spot in a sticker breakout was on the order of 3 to $10 \mathrm{sec}$. It also showed that the hot spot in a sticker breakout travels at a speed equal to one-half the casting speed and therefore the constant speed withdrawal cycle is set to ensure that the hot spot does not come close to the mold exit which would create a breakout.

The second problem was surface quality. Although this is not a critical factor for rheocasting since most material produced is reheated into the liquid-solid region and reformed into desired parts with the original cast surface disappearing, it was desirable to improve the surface quality in case the original cast surface was required for some applications. Figure 1 illustrates the surface of a typical rheocast bar before improvements. Six distinct types of surface appeared on cast bar and 


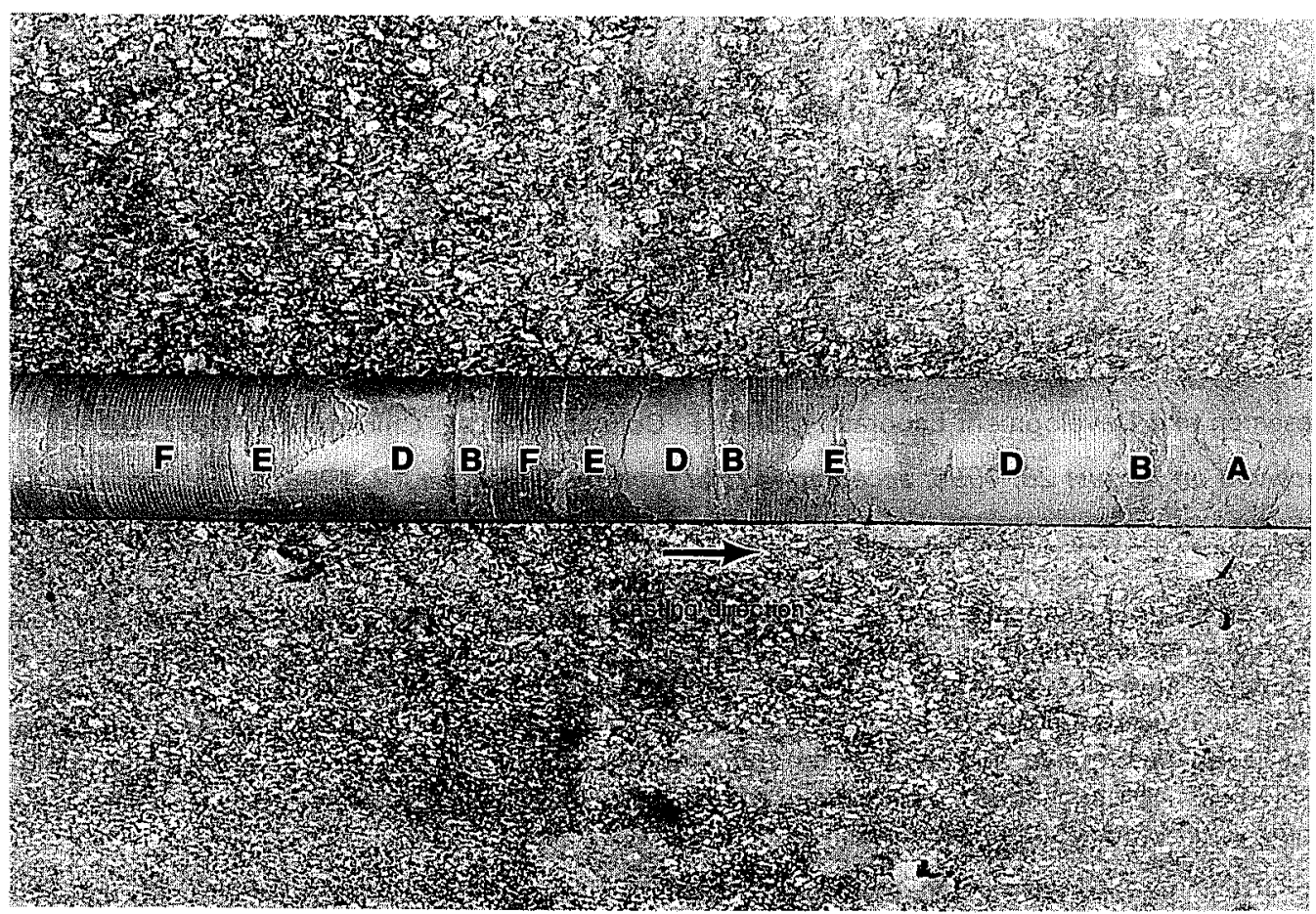

Fig. 1. Photograph of the surface features of a rheocast bar before improvements.

five are shown in this figure. The area marked, $\mathrm{A}$, is typical of the mold filling process which occurs at the beginning of a heat. Areas $\mathbf{B}$ are relatively smooth surfaces which reproduce the geometry of the breakring employed and are called breakring marks. Areas D are very smooth surfaces which would be desirable for the entire cast surface. Areas $\mathrm{E}$ are irregular laps and bleeds, and areas $\mathrm{F}$ are oscillation marks. Areas $\mathrm{C}$ which do not appear on the figure are a rough surface without oscillation marks. The surface quality problem has also been solved by moving to the new withdrawal cycle and by causing the solidification to occur only on the smooth breakring surface.

These two improvements have been accomplished because it was possible to determine the solidification mechanism in the rheocaster and predict changes in the operating characteristics based on this mechanism. The mechanism for solidification in the rheocaster and some other observations about solidification are detailed below.

\section{Description of Rheocaster}

To understand the mechanism of solidification in a rheocaster, it is important to first understand the way in which it operates. Figure 2 is a schematic of the rheocaster. From top to bottom, it consists of a small tundish which is attached with refractory gaskets to a stirring chamber by means of a constricted opening to prevent the formation of a vortex traveling from the stirring chamber into the tundish due to the high stirring rates in the stirring chamber. The stirring chamber is a water cooled stainless steel shell which has a ceramic liner. The stirring chamber has a constriction at the bottom to prevent the propagation of secondary stirring loops into the mold region. The stirring chamber has a larger diameter than the mold in order to maximize the rotational velocity and hence the shear rate of the

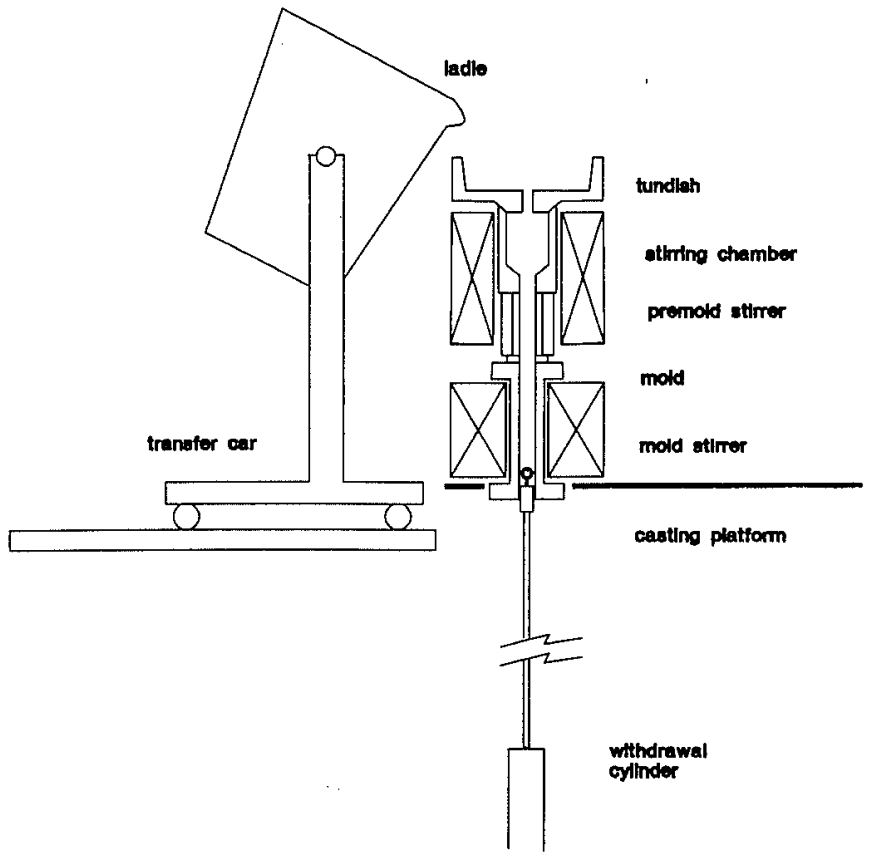

Fig. 2. Schematic of the rheocaster identifying component parts.

dendrites at the solidification front. The interior diameter of the stirring chamber is $152.4 \mathrm{~mm}$ and it is $381 \mathrm{~mm}$ from the top of the stirring chamber to the constriction in the bottom of the stirring chamber. From the constricted region, in the stirring chamber the metal then flows into a hot pipe region which is a highly insulated ceramic section of the caster which has the same nominal diameter as the mold, $76.2 \mathrm{~mm}$. The length of the constricted region of the stirring chamber and the hot pipe is $279.4 \mathrm{~mm}$. At the end of the hot pipe section is a boron nitride breakring which also has the same nominal diameter as the mold and is anywhere from 6 to $25.4 \mathrm{~mm}$ thick. The final section of the rheocaster is the stainless 
steel or copper-beryllium mold which has a stirring coil around its periphery. The mold is again $76.4 \mathrm{~mm}$ in diameter and $381 \mathrm{~mm}$ long. The withdrawal system is a hydraulic cylinder that could be extended approximately $2.4 \mathrm{~m}$. This type of system was used to allow the bar to oscillate or be withdrawn using various patterns while maintaining a fixed position for the stirring chambermold system.

\section{Operation of Rheocaster}

Approximately $100 \mathrm{~kg}$ heats were used for each cast because this was the approximate weight of the $2.4 \mathrm{~m}$ long, $76.2 \mathrm{~mm}$ diameter bar that could be made on the caster due to the maximum extraction length of the withdrawal system. At the beginning of the cast, a dummy bar is inserted about $50 \mathrm{~mm}$ into the casting mold to provide a physical attachment to the withdrawal device and to contain the initial liquid before a solid steel shell is formed. When the desired temperature is reached in the ladle, steel is poured into the rheocaster. At this time, the stirrers are not activated. After about $10 \mathrm{sec}$ the stirrers are activated and the first withdrawal cycle is initiated. It is assumed that the liquid steel level in the machine is above the top of the breakring when both actions are started. The withdrawal cycle, Fig. 3, was originally repeated at a frequency of $3 \mathrm{~Hz}$ with a small fraction of each cycle devoted to a hold time and pushback. The frequency has now been significantly reduced and each cycle is normally a ten second withdrawal at $1.0 \mathrm{~m} / \mathrm{min}$, a push back of one $\mathrm{mm}$ and a hesitation of $10 \mathrm{sec}$. This cycle is then repeated until the cast is complete. This gives an effective withdrawal rate of $0.5 \mathrm{~m} / \mathrm{min}$. This current withdrawal cycle was established as a result of the investigative work detailed in this paper.

\section{Discussion of Solidification Mechanism}

The mechanism for solidification in the rheocaster can be followed in detail by referring to Fig. 4 . This figure shows the solidification mechanism for a total of $40 \mathrm{sec}$ from the onset of the cast. At this time a steady state process is established and the process merely repeats itself. In Fig. 4, the solidification process is shown at 6 different times in this $40 \mathrm{sec}$ interval.

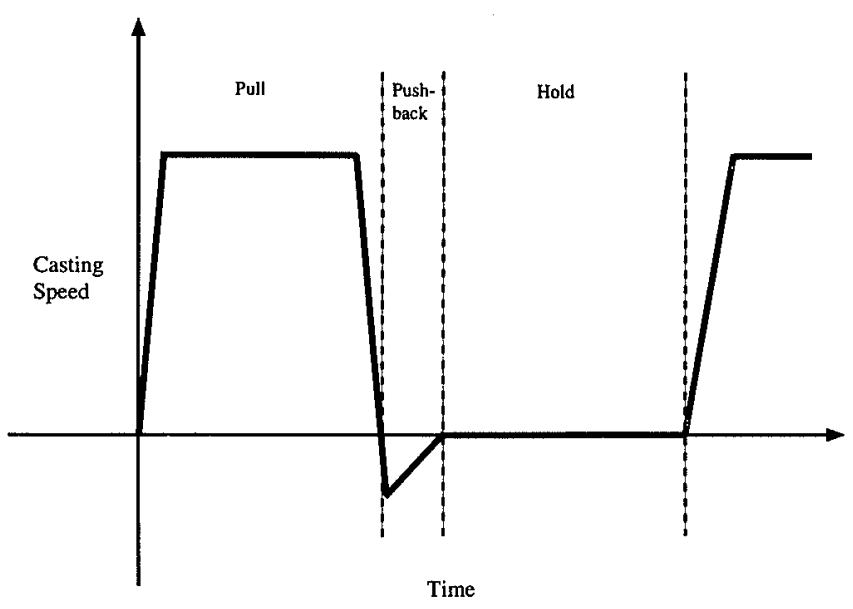

Fig. 3. Typical withdrawal pattern for the rheocaster.
The first increment, shown in Fig. 4(a), is what the solidified shell looks like just as the first withdrawal cycle is initiated. At this time, from the dummy bar up to the breakring, a solid steel shell has formed in stationary solidification against the copper mold and a similar shell has formed in stationary solidification against the breakring. It is also assumed that the liquid level has reached a level above the breakring and some stationary solidification has occurred on the hot pipe.

Within a very short time after Fig. 4(a), the liquid level in the machine has increased and may even be in the tundish. As the withdrawal cycle is initiated the upper portion of the steel shell, above point $X$, adheres to the rough hot pipe material as the stronger and thicker shell below it is removed by the withdrawal mechanism. The thin, hot, and hence weak portion of the steel shell below point $X$, where there is adherence to the hot pipe, will be plastically deformed in a gauge length that has been shown to be on the order of magnitude of $4 \mathrm{~mm}$ in previous experiments ${ }^{2)}$ and act just like a tensile specimen. The lower part of the shell below the gauge length of $4 \mathrm{~mm}$ will be thicker, colder and hence stronger and not plastically deform but move with the solid shell below it being withdrawn at a casting speed of $1.0 \mathrm{~m} / \mathrm{min}$. A thin spot will form in the center of the $4 \mathrm{~mm}$ gauge length as it is plastically deformed and since it is attached to a stationary point above the thin spot and moving at $1.0 \mathrm{~m} / \mathrm{min}$ below the thin spot, it will travel at a speed of $0.5 \mathrm{~m} / \mathrm{min}$ down the length of the mold. This thin section while deforming will be pressed into the rheocaster substrate and reproduce its features due to the low strength and thin shell, and will eventually rupture. Hot metal will rush into the void and a new thin section will solidify and form a new thin, approximately $4 \mathrm{~mm}$ long section, along the hot pipe surface which will then become the new gauge length for the next cycle of plastic deformation and failure. The liquid steel will be under a high ferrostatic head when it goes through the void caused by the fracture and will accurately reproduce the features of the rheocaster substrate it solidifies against. The plastically deformed material from the previous cycle both above and below this newly formed section is stronger than the newly formed section and is no longer plastically deformed after the rupture. The process, shown in Fig. 5, will continually repeat itself at the traveling thin spot in the shell while the strand is being withdrawn at a constant speed. This thin spot will be the hottest point on the steel shell and will offer the least resistance to heat flow into the rheocaster solidification substrate surface. Hence this spot will be called the "hot spot" from this point on to correspond with terminology used for conventional continuous casting. This phenomena repeating itself will mean that ruptures of the $4 \mathrm{~mm}$ gauge will occur on the order of every $2 \mathrm{~mm}$ on the cast surface and that an equal amount of surface created by plastic deformation and liquid filling will occur below and above the hot spot. It manifests itself on the surface of the as-cast bar as faint marks spaced at approximately $2 \mathrm{~mm}$ intervals. In general, they are quite visible when solidification takes place on the mold but not when the solidification takes 

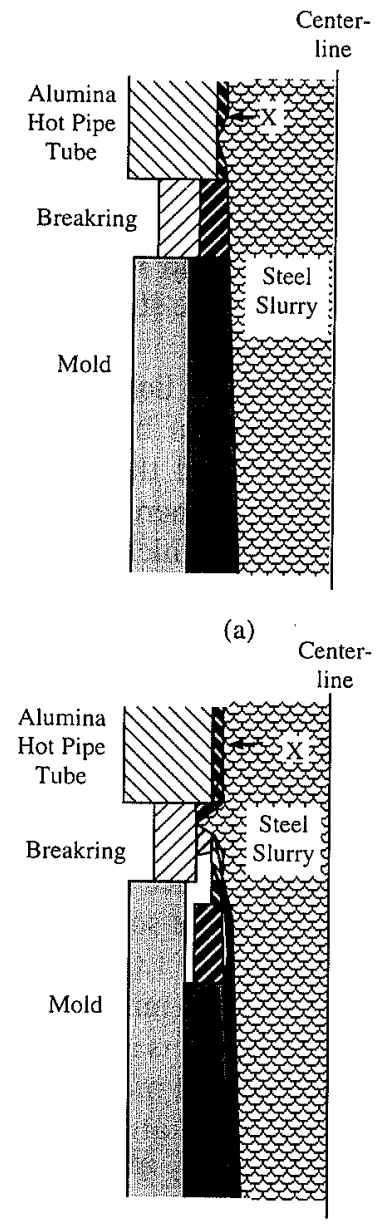

(c)

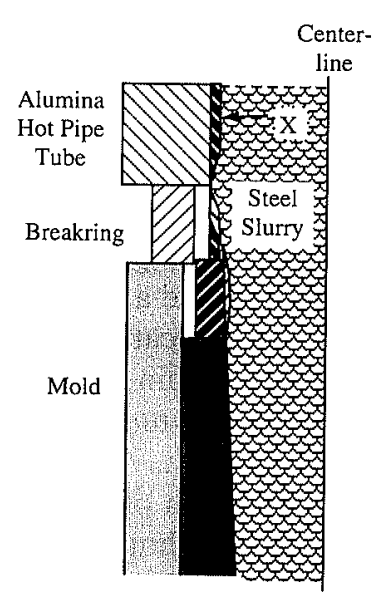

(b)

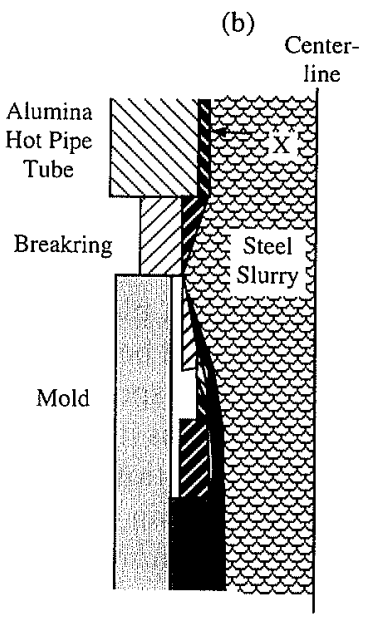

(d)

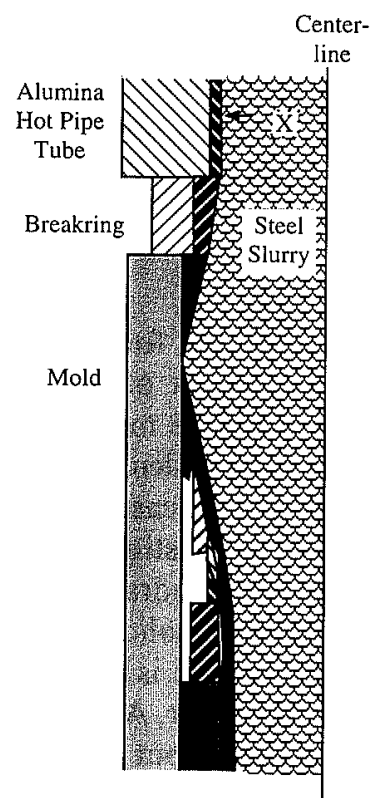

(e)

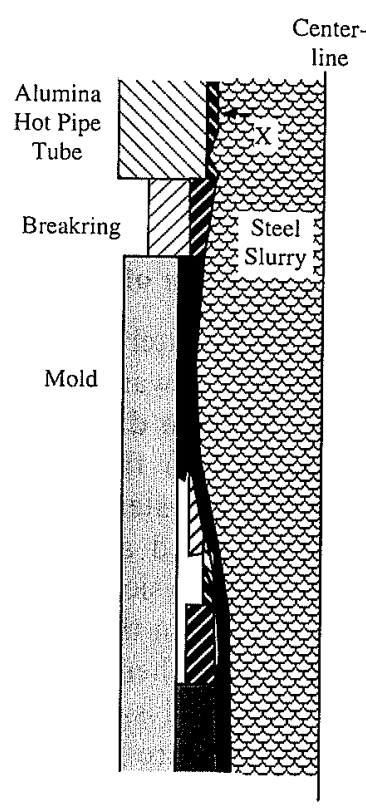

(f)

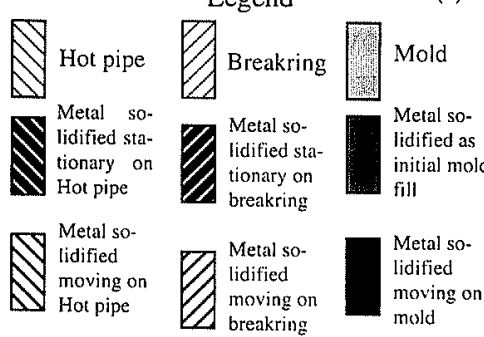

Fig. 4. Development of the various surface features on a rheocaster bar cast at $0.5 \mathrm{~m} / \mathrm{min}$ and with a $10 \mathrm{sec}$ pull, $10 \mathrm{sec}$ hold withdrawal cycle. (a) start of the first withdrawal stroke; (b) $1.4 \mathrm{sec}$ into the withdrawal stroke, hot spot about to move onto the breakring; (c) $2.0 \mathrm{sec}$ into the withdrawal stroke, hot spot is on breakring; (d) $6 \mathrm{sec}$ into the withdrawal stroke, hot spot is about to move onto the mold; (e) $10 \mathrm{sec}$ into the withdrawal stroke, the bar is stopped and pushed back $2 \mathrm{~mm}$; (f) 20 into the withdrawal cycle at the start of the next cycle, the bar has been held for $10 \mathrm{sec}$, the weak spot has healed and a new one created on the hot pipe.

place on the hot pipe or breakring. These faint marks are called secondary witness marks and should not be confused with surface characteristics formed on conventional horizontal caster product. Their origins are of a different nature.

Once one spot on the casting substrate has stuck and created point X, Fig. 4, this point will propagate around the periphery of the cross section of the casting. If the periphery is very small, such as the approximately $163 \mathrm{~mm}$ for a $76 \mathrm{~mm}$ round for the current rheocaster design, the hot spot will be approximately a straight line around the section of the casting. As this number increases, and certainly at values of around $1000 \mathrm{~mm}$, the stress on the shell will lead to a hot spot line being at an angle of about $45^{\circ}$ from the point of the initial sticking.

Figure 4(b), shows the steel shell and the location of the hot spot after approximately $1.4 \mathrm{sec}$. At this time the hot spot has traveled to a point right at the intersection of the hot pipe and the breakring. Equivalent lengths of plastically deformed and ruptured surface both above and below the hot spot equivalent to the distance from $\mathrm{X}$ to the breakring, approximately $12 \mathrm{~mm}$ have been formed that reproduce the features of the hot pipe. The

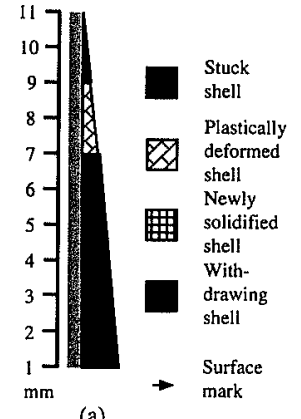

(a)

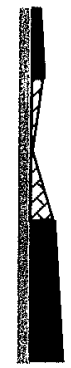

(b)

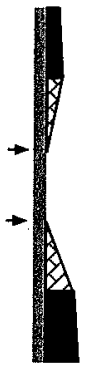

(c)

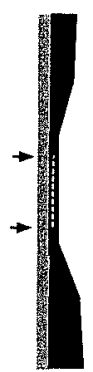

(d)

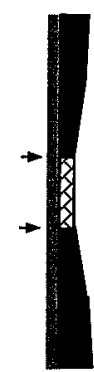

(e)

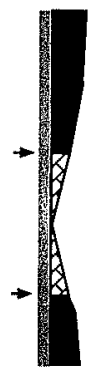

(f)

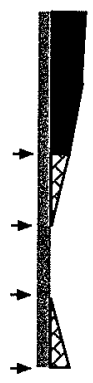

(g)

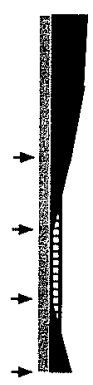

(h)
Fig. 5. Development of the secondary witness marks. 
amount of newly created cast surface is about $24 \mathrm{~mm}$ since the withdrawal mechanism would have moved this far during this time at a speed of $1.0 \mathrm{~m} / \mathrm{min}$. All of the rest of the cast features shown in Fig. 4(a) have moved down approximately $24 \mathrm{~mm}$.

Operationally, to prevent casting a thick section in the upper part of the rheocaster and having to withdraw this thick section through a smaller section later, the caster is assembled with the hot pipe being slightly smaller in diameter than the breakring. Likewise the breakring is smaller in diameter than the mold so that wedging and jamming of the cast product will not occur. This design feature is shown in Fig. 4 and is exaggerated to make it obvious to the reader.

Figure 4(c) shows the cast steel shell at a time of about $2 \mathrm{sec}$ after Fig. 4(a). At this time, the hot spot has moved from the hot pipe to about $12 \mathrm{~mm}$ down the breakring. Since there is a mismatch in the diameters of the two sections of the caster, the liquid pushing through the rupture in the shell caused by the plastic deformation of the steel shell near the hot spot will fill the void it finds as the shell deforms around the mismatch in diameters and form a lap on the surface of the cast bar. Once the hot spot is entirely on the breakring a lap will not occur.

Figure 4(d) shows the cast steel shell that has been formed at $6 \mathrm{sec}$ in the constant velocity portion of the withdrawal cycle at $1.0 \mathrm{~m} / \mathrm{min}$. At this time the withdrawal system has moved about $100 \mathrm{~mm}$ and the hot spot has moved about $50 \mathrm{~mm}$ putting the hot spot right on the intersection of the breakring and the copper mold. This means that above and below the hot spot $38 \mathrm{~mm}$ of steel shell has been created by plastic deformation and rupture (hot spot solidification) on the breakring and $12 \mathrm{~mm}$ of hot spot solidification on the hot pipe. This results in a length of $76 \mathrm{~mm}$ of hot spot solidification on the breakring in the center of which is the hot spot itself. Above and below this $76 \mathrm{~mm}$ area is a $12 \mathrm{~mm}$ length of hot spot solidification formed on the hot pipe. All of the features shown on Fig. 4(a) have now moved down $100 \mathrm{~mm}$ in Fig. 4(d) from their location in Fig. 4(a) with the withdrawal mechanism.

Figure 4(e) shows the cast steel shell at the end of the constant speed portion of the withdrawal cycle at a time $10 \mathrm{sec}$ after Fig. 4(a). At this point, the hot spot has moved a total of $83 \mathrm{~mm}$ below its point of origin in the hot pipe section, and is $33 \mathrm{~mm}$ below the intersection of the breakring and mold. Above and below the hot spot there has been $33 \mathrm{~mm}$ of steel shell created by plastic deformation and rupture (hot spot solidification) on the mold, $38 \mathrm{~mm}$ of hot spot solidification on the breakring and $12 \mathrm{~mm}$ of hot spot solidification on the hot pipe. This results in a length of $66 \mathrm{~mm}$ of hot spot solidification on the mold in the center of which theoretically is the hot spot itself. In practice, the hot spot tends to be closer to the dummy bar end of the cast. Above and below this $66 \mathrm{~mm}$ area is a $38 \mathrm{~mm}$ length of hot spot solidification on the breakring and a $12 \mathrm{~mm}$ length of solidification formed on the hot pipe. All features shown on Fig. 4(a) have now moved down $166 \mathrm{~mm}$ from their location on Fig. 4(a) as a result of the movement of the withdrawal mechanism. Therefore a total of $166 \mathrm{~mm}$ of new surface has been created but the entire new surface created has been through hot spot solidification.

After the constant speed portion of the withdrawal cycle, a pushback of 1 to $2 \mathrm{~mm}$ is performed. This is to try to accommodate the shrinkage that will occur in the shell while the motion of the bar has been terminated. Because the shell is cooling down while being held in a fixed position at both the front and back ends of the cast bar, the bar will shrink and create a large tensile stress near the hot spot. Concurrently, solidification is occurring at the hot spot and it is growing thicker. The stress will cause a crack to form in the shell near the point of the hot spot and the pushback will minimize the amount of cracking. Even in the best cases, however, some plastic deformation will occur and the primary witness mark will be formed. This witness mark may have a crack in it if the pushback has not been of sufficient magnitude. It should be noted that this primary witness mark which occurs in rheocasting does not have the same mechanism for its origin as in conventional horizontal casting and should not be confused with the surface characteristic found in that process.

The bar is now held for $10 \mathrm{sec}$ without any motion. During this time very rapid solidification will occur near the hot spot (primary witness mark) because it is adjacent to a water cooled copper mold. The solidification rate will be significantly higher than for other portions of the bar not in contact with the mold surface. After the $10 \mathrm{sec}$ hold, due to this difference in cooling rate between the hot spot and other areas of the shell, another point on the shell will become the weakest and thinnest section. Previous work ${ }^{3)}$ has shown that the dwell time must be approximately 3 to $6 \mathrm{sec}$ for the shell to thicken sufficiently to become thicker than a portion of the shell higher in the rheocaster. In Fig. 4(f), it is assumed that this location is at the same spot that the hot spot was initiated in Fig. 4(a). When the next constant speed portion of the withdrawal cycle is initiated, the stress will be highest at this thinnest portion of the shell and it will crack and become the location of the hot spot which will now propagate down the mold during the constant speed portion of the withdrawal cycle.

If the hold period after the constant speed portion of the withdrawal cycle is not sufficiently long, the weakest and thinnest section of the cast steel shell might still remain at the original hot spot. If this happens, upon initiating the next constant speed segment, the hot spot will not change position and it will start propagating down from its former position. When the hot spot gets near to the exit of the mold the steel shell will be too thin and weak to support the ferrostatic head and the thin portion of the shell outside the mold will rupture causing a breakout of liquid metal and hence a termination of the cast.

Forty seconds after Fig. 4(a) two complete withdrawal cycles will have been completed. This process will repeat itself over and over again as the rheocasting process continues. It should be pointed out that the location of the new hot spot after the start of a new cycle may change position from one cycle to the next and that for simplicity, it has been assumed that it starts at the same location 
in Fig. 4.

Figure 6 shows how the steel shell will look at the end of the constant speed portion of the withdrawal cycle for three different initiation points of the hot spot in steady state casting. It was assumed that the hot spot always initiated in the same spot on each cycle for these diagrams. Figure 6(a) is for hot spot initiation at the intersection of the hot pipe and breakring. Figure 6(b) is for hot spot initiation half way down the breakring and Fig. 6(c) is for initiation at the bottom of the breakring and start of the mold. It can be seen that significantly different surface morphologies will be produced for these four patterns. However, the distance between primary witness marks will always be about 166 millimeters.

The evidence of the existence of the structures described above is shown in Fig. 7. Figure 7(a) illustrates the microstructure at a lap between surfaces of types $C$ and $D$ as previously described with the $D$ type surface being on top and above this micrograph and not shown. This is the type of structure that would be formed as shown in Fig. 4(c). The lap over this type $C$ surface is appears to be a rapidly chilled overflow. Based on this micrograph of the $C$ type surface with an overfiow, the rough nature of the $\mathrm{D}$ type surface found above this micrograph, and the ceramic particles embedded in the $\mathrm{D}$ type surface, it is apparent that the D type surface was solidified as a skull in the hot pipe. Later in the casting process this skull became attached to the cast bar and was pulled out of the hot pipe. Upon reaching the breaking, metal overflowed the top of the skull (because the breaking had a larger diameter than the hot pipe) causing the lap as shown in Fig. 4(c).

Figure 7(b) indicates the type of structure that is

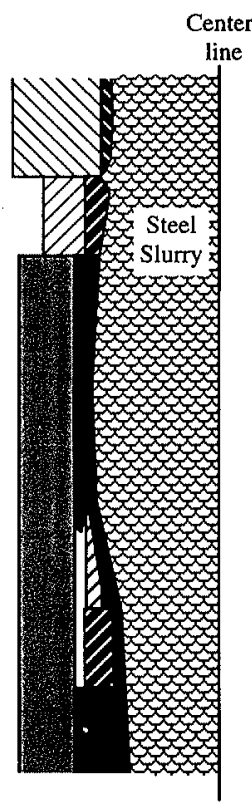

(a)

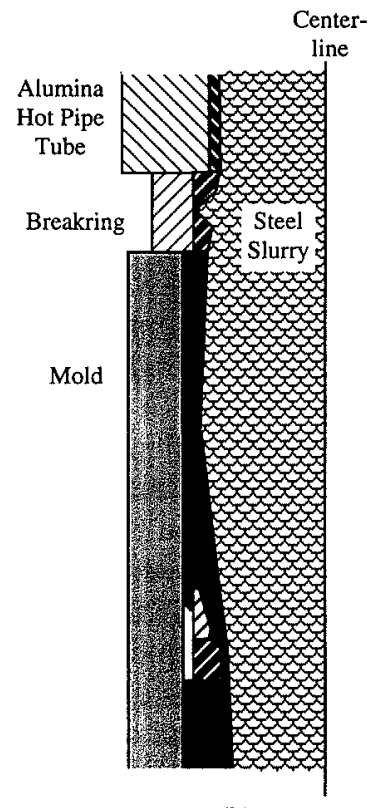

(b)

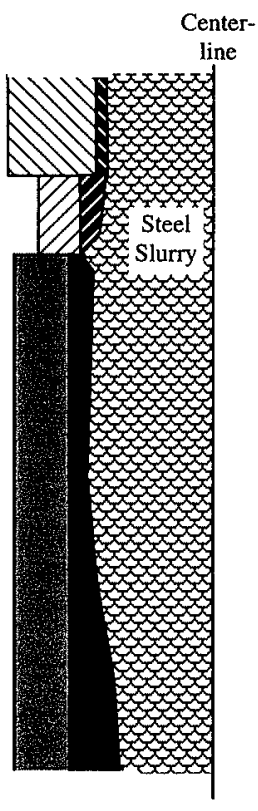

(c)

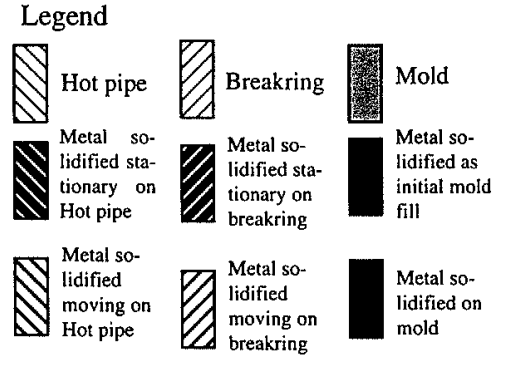

Fig. 6. Surface patterns found when the weak spot occurs at; (a) top of the breakring; (b) halfway down the breakring and; (c) at the bottom of the breakring.

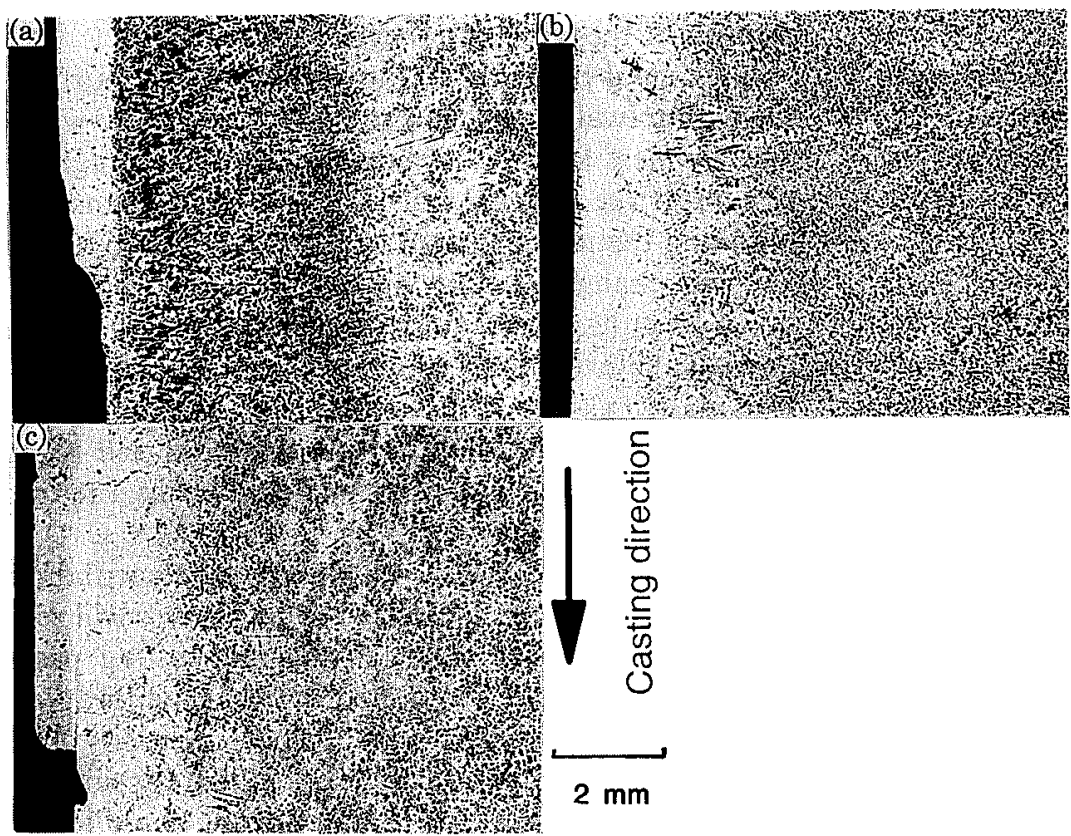

Fig. 7.

Longitudinal micrographs of the surface of a typical cast before improvements: (a) lap between surfaces of types $C$ and $D$; (b) surface of type D and; (c) lap between surfaces of types $\mathrm{D}$ and $\mathrm{E}$. 
formed for the type D surface which is solidified on the breakring. It is very smooth and indicative of the surface formed in Fig. 4(d).

Figure $7(\mathrm{c})$ indicates the type of structure that is formed near a lap between surface types $D$ and $E$ with the microstructure of surface $\mathrm{D}$ being shown, and the microstructure of surface $\mathrm{E}$ would be above this area and is not shown. This lap would occur as shown schematically in Fig. 4(e) and occurs as the hot spot moves from the breaking onto the mold since the diameter of the mold is larger than the diameter of the breakring.

\section{Verification of Model}

The above model has been verified by measuring the distance between surfaces characteristics on as-rheocast bars. The distances have then been compared to those that would be predicted from the above theory to see if there was any correlation. The results of this analysis appear in Table 1. All the casts examined were cast at about $0.45 \mathrm{~m} / \mathrm{min}$ and the withdrawal cycles used were the following; a $10 \mathrm{sec}$ withdrawal followed by $10 \mathrm{sec}$ hold, $6 \mathrm{sec}$ withdrawal followed by $6 \mathrm{sec}$ hold, $4.5 \mathrm{sec}$ withdrawal followed by $4.5 \mathrm{sec}$ hold, and finally $3 \mathrm{sec}$ withdrawal followed by $3 \mathrm{sec}$ hold. For each of the casts examined in this table, the weak point at the beginning of each cycle occurred either on the breakring or at the

Table 1. Theoretical and measured values of the dimensions of the various surface features on rheocast bars.

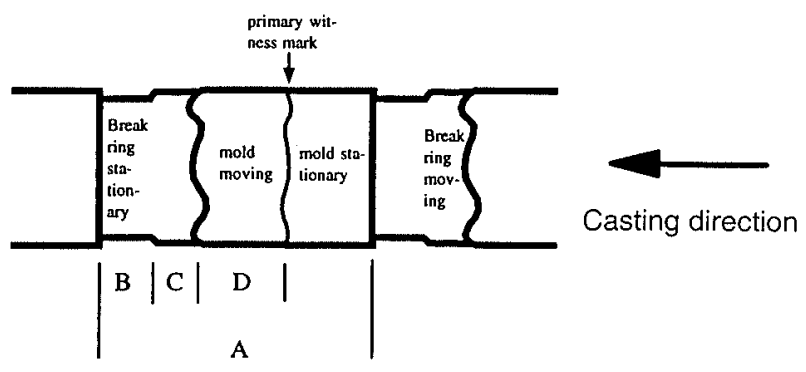

\begin{tabular}{|c|l|c|c|c|c|c|c|}
\hline \multicolumn{2}{|c|}{ Cast } & \multicolumn{1}{|c|}{$\begin{array}{c}\text { A } \\
(\mathrm{mm})\end{array}$} & $\begin{array}{c}\text { B } \\
(\mathrm{mm})\end{array}$ & \multicolumn{2}{c|}{$\begin{array}{c}\text { C } \\
(\mathrm{mm})\end{array}$} & \multicolumn{2}{c|}{$\begin{array}{c}\text { D } \\
(\mathrm{mm})\end{array}$} \\
\cline { 2 - 9 } & Actual & Actual & $\begin{array}{c}\text { Theor- } \\
\text { etical }\end{array}$ & Actual & $\begin{array}{c}\text { Theor- } \\
\text { etical }^{2}\end{array}$ & Actual \\
\hline \multirow{2}{*}{74} & Begining & 147 & 38 & 38 & 33 & 38 & 25 \\
\cline { 2 - 9 } & End & 147 & 20 & 20 & 33 & 48 & 20 \\
\hline \multirow{2}{*}{81} & Begining & 96 & 38 & 38 & 25 & 18 & 8 \\
\cline { 2 - 9 } & End & 96 & 25 & 25 & 18 & 28 & 10 \\
\hline \multirow{2}{*}{79} & Begining & 74 & 25 & 25 & 23 & 13 & 8 \\
\cline { 2 - 9 } & End & 71 & 15 & 15 & 25 & 15 & 10 \\
\hline
\end{tabular}

$\mathbf{I}=\mathbf{B}$

$2=0.5 *(A-(B+C))$

3 Segments $B$ and $C$ could not be distinquished.

4 Occasional patches of mold surface in bar. hotpipe-breakring junction. For most of the casts, the weak point occurred at the hotpipe-breakring junction ( $B=37 \mathrm{~mm}$ ) at the beginning of the cast and then migrated to a point about 18 to $25 \mathrm{~mm}$ above the bottom of the breakring toward the end of the casts. This is probably because the breakring is backed by a thermally conductive piece of graphite for its lower $18 \mathrm{~mm}$ and by an insulating piece of silica brick for its upper $18 \mathrm{~mm}$.

From the above discussion the length of surface that solidifies dynamically on the breakring ( $C$ in Table 1) should be the same as the distance from the bottom of the breakring to the weak spot ( $B$ in Table 1) i.e., $B=C$. While this appears to be true at the beginning of each cast (the hot spot migrates down the breakring at about 0.52 times the casting speed), it does not appear to be true towards the end of the casts. At the end of the casts, the hot spot appears to migrate at approximately 0.4 times the casting speed. Similarly, the hot spot does not appear to travel down the mold at the predicted 0.5 times the casting speed. If the hot spot traveled down the mold at 0.5 times the casting speed, the amount of metal solidified above the primary witness mark (stationary solidification on the mold) would be equivalent to the amount of metal solidified below the primary witness mark (moving solidification on the mold) and hence the length of these two areas would be equal to $(0.5 \cdot(A-(B+C)))$ as shown in Table 1. The hot spot appears to travel at about 0.7 times the casting speed. This rate of migration does not seem to change as the cast progresses.

\section{Heat Transfer Analysis}

For conventional continuous casters it has been found that the mold heat transfer rate (MHTR) will vary as a function of casting speed and steel composition with carbon content having the greatest effect on MHTR. ${ }^{4)}$ The MHTR can be determined for the rheocaster because the water flow rate into the mold and the inlet and outlet temperatures are monitored. Figure 8 shows the plot of MHTR vs. casting speed for four different steel grades. At this time it is not evident that the steel grade has any significant effect on MHTR.

For conventional continuous casting, the surface morphology will change depending on the carbon content. Carbon levels of about $0.1 \%$ will show a significant rippling of the external skin which means that when they solidify only a fraction of the steel shell that is in close contact with the copper mold. For carbon contents both above and below this level, the rippling decreases and the MHTR returns to a level that is about the same for both high and low carbon steels. It has been shown in the past that if the meniscus could be pressurized for conventional continuous casting, the MHTR for $0.10 \%$ carbon steels could be increased to the same level or higher than other carbon steels.

Figure 8 also contains a MHTR vs. speed plot for a $0.5 \%$ carbon steel cast using conventional continuous casting. It is apparent that the MHTR is higher for the rheocaster and that there is no difference for different carbon levels. This is probably due to the fact that the steel shell is being formed with a least $300 \mathrm{~mm}$ of fer- 

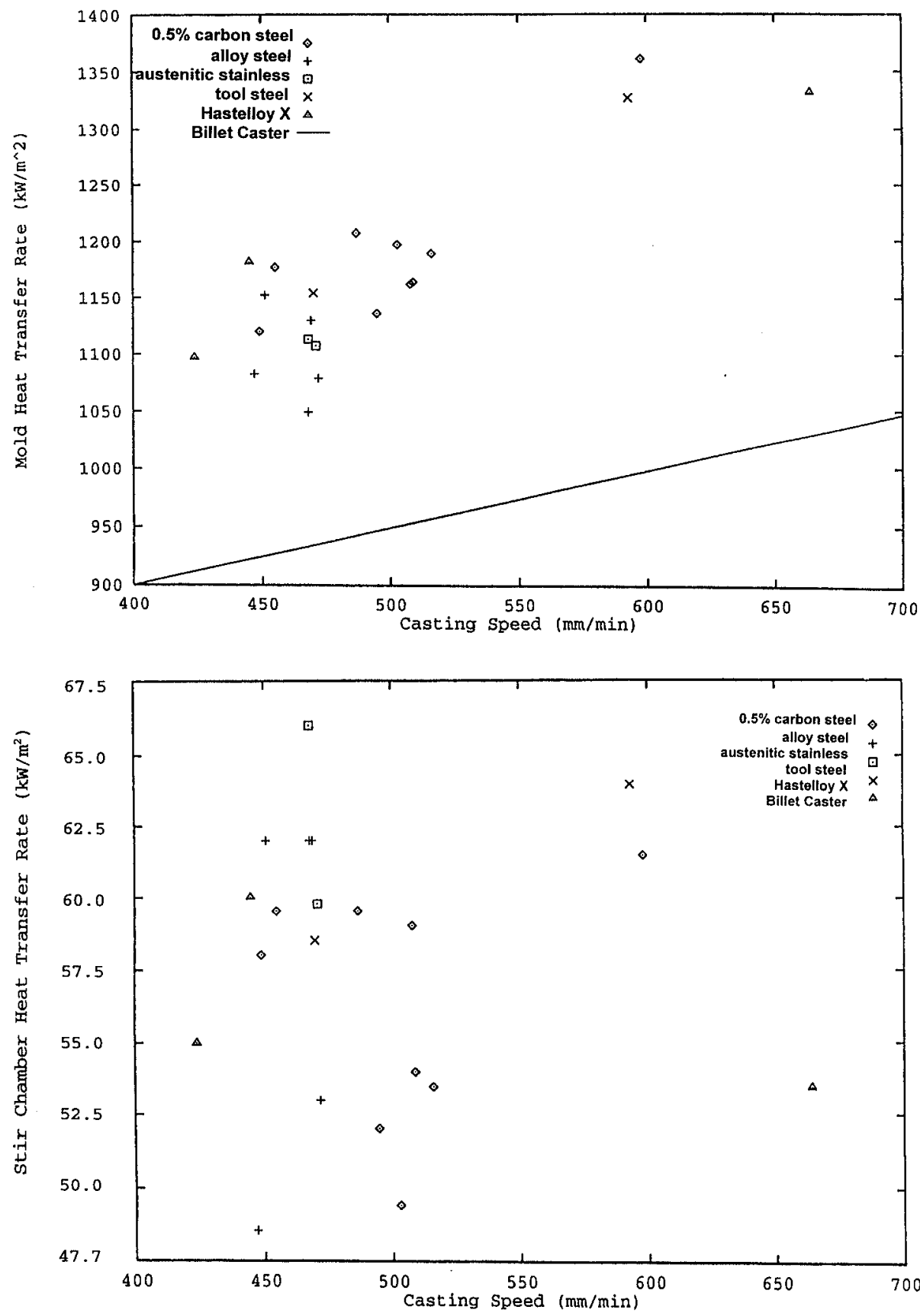

Fig. 8.

Mold heat transfer rate $v$ s. casting speed for various grades cast in the rheocaster.
Fig. 9.

Stir chamber heat transfer $v$ s. casting speed for various grades cast in the rheocaster. rostatic head which is equivalent to pressurizing the meniscus. This high pressure is providing more close contact of the solidifying steel to the copper mold by mechanically deforming the thin, weak steel shell and preventing any rippling that might tend to occur.

The heat transfer rate is also monitored on the rheocaster for the stirring chamber. A plot of this variable vs. casting speed for several grades is also included, Fig. 9. However, there is no apparent correlation of the MHTR in the stirring chamber with either steel composition or casting speed.

Figure 10 is a plot of the mold outlet water temperature which is directly proportional to the MHTR for a cast made on the rheocaster where the withdrawal cycle was a constant speed withdrawal of $1.0 \mathrm{~m} / \mathrm{min}$ for $10 \mathrm{sec}$, a push back of $2 \mathrm{~mm}$ and a hold period of $10 \mathrm{sec}$. From this plot it is obvious that the hot spot starts out on either the breakring or hot pipe and migrates onto the

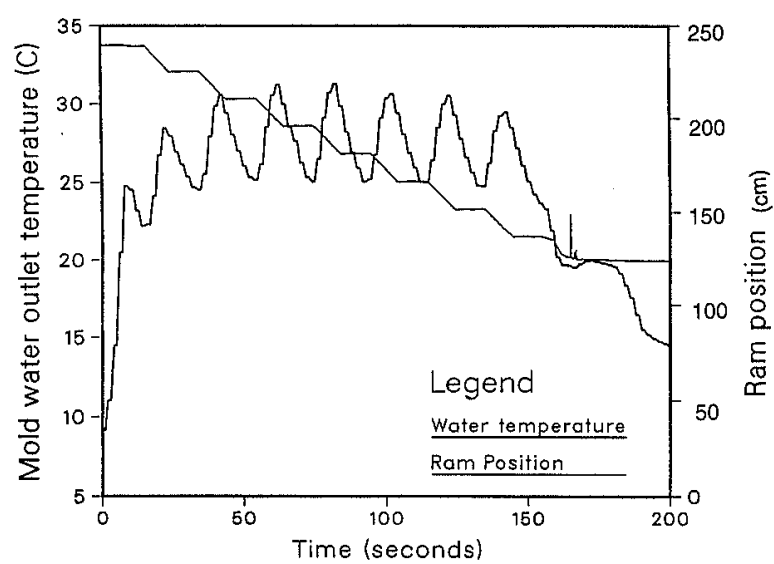

Fig. 10. Mold outlet water temperature and withdrawal ram position vs. time for a $10 \mathrm{sec}$ pull, $10 \mathrm{sec}$ hold withdrawal pattern. Overall cast speed was $0.45 \mathrm{~m} / \mathrm{min}$. 
mold. It can be noted that the MHTR is lowest at the beginning of the withdrawal cycle. As the constant speed portion of the cycle continues, the MHTR increases as the hot spot comes into the mold and continues to increase when a larger portion of the shell is thin in the mold as the hot spot moves down further into the mold. When the constant speed portion of the withdrawal cycle ends, the MHTR decreases as the shell thickens and remains low once the hot spot is reinitiated on the breakring or hot pipe. The MHTR again increases every time the hot spot reaches the mold.

Figure 11 is a plot similar to Fig. 10 except for an altered cycle with the constant speed portion of the withdrawal cycle being for $3 \mathrm{sec}$ at $1 \mathrm{~m} / \mathrm{min}$. The pushback is again $2 \mathrm{~mm}$ and the hold time is for $3 \mathrm{sec}$. In this case, as mentioned above in the discussion of the solidification mechanism, the hot spot never travels down onto the mold. Therefore there are no large swings in the mold outlet temperature as noticed for the previous cast.

It should be noted that the MHTR numbers plotted in Fig. 8 were average values of the MHTR for the cast during steady state operation and that those values did not change as a function of the parameters of the withdrawal cycle. They were only a function of casting speed. This can be seen by comparing Figs. 9 and 10 and by noting that a smoothed line drawn between the peaks and valleys of the MHTR vs. time plot would be the same for both figures since the casting speed was the same.

\section{Discussion}

Based on the above determination of the solidification mechanism it is then obvious that the surface morphology of a rheocast bar should be a combination of the morphologies indicated in Fig. 6. This is indeed true and can be observed in Fig. 1.

It should be pointed out that the hot spot which forms and propagates during each withdrawal cycle of a rheocaster is unique when compared to the other types of continuous casting processes for steel, conventional continuous casting and horizontal continuous casting. For conventional continuous casting, a hot spot will only

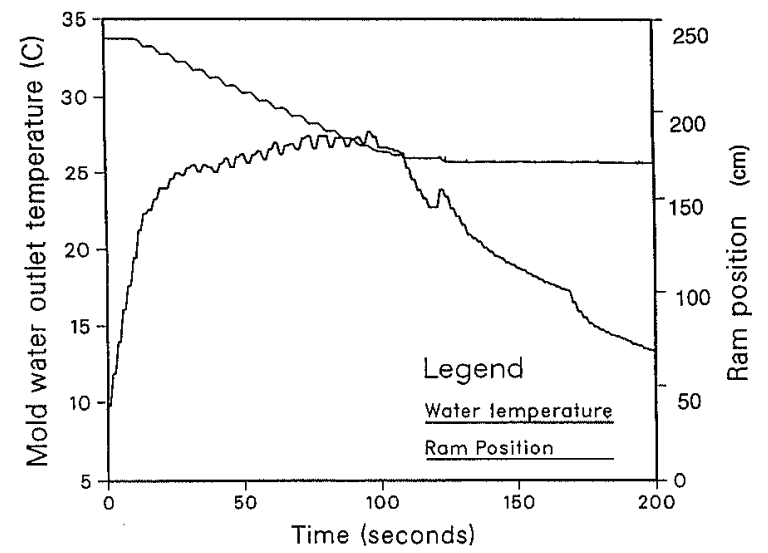

Fig. 11. Mold outlet water temperature and withdrawal ram position $v s$. time for a $3 \mathrm{sec}$ pull, $3 \mathrm{sec}$ hold withdrawal pattern. Overall cast speed was $0.45 \mathrm{~m} / \mathrm{min}$. form when extraordinary conditions exist to initiate either a sticker or hanger type breakout. When a hot spot forms in these instances, the operation of the caster must be altered to allow the hot spot to heal and hopefully release the sticker or hanger and restore normal conditions. For horizontal continuous casters, a hot spot exists during every cycle at some distance downstream from the breakring. It, however, maintains this position and does not propagate further down stream from the breakring in normal conditions as happens in rheocasting. Only when extraordinary operating conditions exist for a horizontal continuous caster will the hot spot propagate down stream and when it does it will usually result in a breakout unless preventative actions are taken to restore the stable nature of the hot spot. Therefore continuous rheocasting is unique in that the hot spot forms during every withdrawal cycle and that the hot spot propagates down stream during the withdrawal cycle and returns back to its starting location at the start of the next withdrawal cycle. This hot spot behavior dictates that the location for initial solidification of the cast surface changes with time for a rheocaster while for conventional continuous casting this always occurs at the meniscus and for horizontal continuous casting it occurs adjacent to the breakring.

By understanding the solidification mechanism and ensuring that the hot spot remained within the mold, sticker breakouts were eliminated. This was accomplished by moving from a withdrawal cycle that had a frequency of approximately $3 \mathrm{~Hz}$ with a negligible hold time and push back distance, to a frequency of less than $1 \mathrm{~Hz}$ with an extended hold time of about $3 \mathrm{sec}$ and pushback of $1-2 \mathrm{~mm}$. This ensured the hot spot was contained within the mold region, and that the hot spot at the end of the withdrawal cycle would thicken, and also, that the newly formed hot spot would initiate near the break ring at the start of the next withdrawal cycle.

Efforts have been made to try to stabilize the hot spot initiation point and optimize surface quality by so doing. It is believed that the best surface quality will be obtained by having the hot spot initiate near the top of the breakring surface, have the hot spot travel to near the bottom of the breakring at the end of its travel, and reinitiate near the top of the breakring at the start of the next cycle of withdrawal. This is due to the fact that the best cast surface quality is obtained on the breakring surface. Since the final breakring design is about $38 \mathrm{~mm}$ long, to produce this pattern the cooling and insulation for the breakring has to be configured to initiate the hot spot at the top of the breakring. This has been attempted and has been successful. It is also necessary to change the duration and speed of the constant speed portion of the withdrawal cycle to give a total withdrawal distance of less than $76 \mathrm{~mm}$ so that the hot spot will only move approximately $38 \mathrm{~mm}$ at the end of the constant speed withdrawal and still be on the breakring before the new hot spot is initiated at the top of the breakring in the next cycle. This means that the duration of the constant speed portion of the withdrawal cycle must be somewhat less than $5 \mathrm{sec}$ to meet this criterion if the speed is still $1.0 \mathrm{~m} / \mathrm{min}$. In some casts, the point of hot spot initiation 


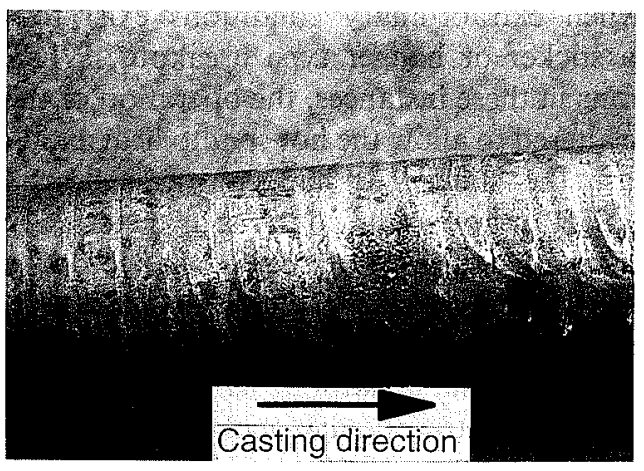

Fig. 12. Photograph of the surface features of a rheocast bar after improvements.

migrates during a cast.

This concept of stabilizing the hot spot solidification on the breakring was used on the rheocaster. The in sulation at the top of the breakring was increased and more intense cooling of the lower part of the breakring was obtained by using a graphite retainer ring behind the outside of the breakring instead of an insulator. This ensured the formation of the hot spot at the end of each cycle at the top end of the breakring. The withdrawal cycle was also altered to be about $3 \mathrm{sec}$ withdrawal followed by $3 \mathrm{sec}$ of no withdrawal and the speed during the withdrawal cycle is about $1 \mathrm{~m} / \mathrm{min}$. The results of these conditions are shown in Fig. 12. The surface quality is drastically improved by keeping the hot spot confined to the breakring and the only surface roughness is some slight laps which occurred when occasionally the hot spot reached the intersection of the breakring and the mold.

\section{Conclusions}

The mechanism for solidification and formation of cast surface morphologies on as-rheocast bars has been formulated and verified by comparing predicted surface morphologies to actual surface morphologies. The mechanism was then used to develop new withdrawal patterns to eliminate sticker breakouts and improve surface quality.

\section{REFERENCES}

1) K. Blazek, J. Kelly and N. Pottore: ISIJ Int., 35 (1995), 813.

2) K. Blazek and I. Saucedo: 4th Int. Continuous Casting Conf. Proc., Brussels, Belgium, (1988), 668.

3) K. Blazek and I. Saucedo: Proc. of Japan-U.S. Cooperative Program Seminar on "Solidification Processing of Advanced Materials," Japan Soc. for Promotion of Sci. and U.S. National Sci. Foundation, Oiso, Japan, (1989), 181.

4) S. Singh and K. Blazek: Open Hearth Proc. (AIME), 57 (1974), 16. 